\title{
Aegilops-Secale amphiploids: chromosome categorisation, pollen viability and identification of fungal disease resistance genes
}

\author{
M. Kwiatek • L. Blaszczyk • H. Wiśniewska • \\ B. Apolinarska
}

Received: 23 May 2011 /Revised: 15 September 2011 /Accepted: 27 September 2011 /Published online: 15 October 2011

(C) The Author(s) 2011. This article is published with open access at Springerlink.com

\begin{abstract}
The aim of this study was to assess the potential breeding value of goatgrass-rye amphiploids, which we are using as a "bridge" in a transfer of Aegilops chromatin (containing, e.g. leaf rust resistance genes) into triticale. We analysed the chromosomal constitution (by genomic in situ hybridisation, GISH), fertility (by pollen viability tests) and the presence of leaf rust and eyespot resistance genes (by molecular and endopeptidase assays) in a collection of $6 \times$ and $4 \times$ amphiploids originating from crosses between five Aegilops species and Secale cereale. In the five hexaploid amphiploids Aegilops kotschyi $\times$ Secale cereale (genome UUSSRR), Ae. variabilis $\times S$. cereale (UUSSRR), Ae. biuncialis $\times S$. cereale (UUMMRR; two lines) and $A e$. ovata $\times S$. cereale $(\mathrm{UUMMRR}), 28$ Aegilops chromosomes were recognised, while in the Ae. tauschii $\times S$. cereale amphiploid (4×; DDRR), only 14 such chromosomes were identified. In the materials, the number of rye chromosomes varied from 14 to 16 . In one line of Ae. ovata $\times S$. cereale, the U-R translocation was found. Pollen viability varied from 24.4 to $75.4 \%$. The leaf rust resistance genes $\operatorname{Lr} 22, \operatorname{Lr} 39$ and Lr41 were identified in Ae. tauschii and the $4 \times$ amphiploid Ae. tauschii $\times S$. cereale. For the first time, the leaf rust resistance gene Lr37 was found in Ae. kotschyi, Ae. ovata, Ae.
\end{abstract}

M. Kwiatek $(\bowtie) \cdot H$. Wiśniewska $\cdot$ B. Apolinarska

Laboratory of Distant Crosses, Institute of Plant Genetics,

Polish Academy of Sciences,

Strzeszyńska 34,

60-479 Poznań, Poland

e-mail: mkwi@igr.poznan.pl

L. Błaszczyk

Laboratory of Metabolomics, Institute of Plant Genetics,

Polish Academy of Sciences,

Strzeszyńska 34,

60-479 Poznań, Poland biuncialis and amphiploids derived from those parental species. No eyespot resistance gene Pch1 was found in the amphiploids.

Keywords Aegilops-Secale - Amphiploids · Eyespot . Genomic in situ hybridisation - Leaf rust $\cdot$ Resistance genes

Fungal diseases of triticale, such as leaf rust (caused by Puccinia triticina) and eyespot (caused by Oculimacula yallundae and $O$. acuformis), have escalated recently. The introgression of effective resistance genes from wild species, like Aegilops spp., is a way to increase the genetic diversity of triticale. Goatgrasses (Aegilops spp.), the wild relatives of wheat and triticale, are a rich source of novel genes for resistance to various pathogens (Gill et al. 1985; Molnár et al. 2005; Prażak 2007; Schneider et al. 2008). Aegilops spp. carry many resistance genes to biotic factors: rusts (Dhaliwal et al. 2002), powdery mildew (Miranda et al. 2007) and eyespot (Leonard et al. 2008), and abiotic factors: drought (Baalbaki et al. 2006) and salinity (Landjeva and Ganeva 1999). The goatgrass-rye amphiploids can be used as a "bridge" to transfer useful agronomic traits from Aegilops spp. to cultivated cereals, like triticale and rye (Wojciechowska and Pudelska 2005).

This research is a first step to increase the genetic diversity of cultivated triticale (Polish cultivars). The major aims of this work were: (1) to analyse the chromosomal constitution of amphiploids by genomic in situ hybridisation (GISH); (2) to evaluate their fertility by pollen viability tests; and (3) to identify leaf rust and eyespot resistance genes in the amphiploids.

Six amphiploid lines, Ae. kotschyi $\times S$. cereale (UUSSRR), Ae. variabilis $\times S$. cereale (UUSSRR), Ae. biuncialis $\times S$. cereale (UUMMRR, two lines), Ae. ovata $\times S$. cereale 
Table 1 Chromosomal constitution in the analysed amphiploids (assessed by genomic in situ hybridisation, GISH) and their pollen viability

\begin{tabular}{|c|c|c|c|c|}
\hline \multirow[t]{2}{*}{ Aegilops-Secale amphiploids } & \multirow[t]{2}{*}{$2 n$} & \multicolumn{2}{|c|}{ Number of chromosomes } & \multirow[t]{2}{*}{ Pollen viability $(\%)$} \\
\hline & & Aegilops spp. & S. cereale & \\
\hline Ae. kotschyi $(\mathrm{UUSS}) \times S$. cereale $(\mathrm{RR})$ & $42-44$ & $28[14 \mathrm{U}+14 \mathrm{~S}]$ & $14-16[\mathrm{R}]$ & 65.7 \\
\hline Ae. variabilis $(\mathrm{UUSS}) \times S$. cereale $(\mathrm{RR})$ & $40-42$ & $28[14 \mathrm{U}+14 \mathrm{~S}]$ & $12,14[\mathrm{R}]$ & 70.6 \\
\hline Ae. biuncialis $($ line 1$)(\mathrm{UUMM}) \times S$. cereale $(\mathrm{RR})$ & 42 & $28[14 \mathrm{U}+14 \mathrm{M}]$ & $14[\mathrm{R}]$ & 75.4 \\
\hline Ae. biuncialis $($ line 2$)(\mathrm{UMM}) \times S$. cereale $(\mathrm{RR})$ & 42 & $28[14 \mathrm{U}+14 \mathrm{M}]$ & $14[\mathrm{R}]$ & 24.4 \\
\hline Ae. ovata $(\mathrm{UUMM}) \times S$. cereale $(\mathrm{RR})$ & 42 & $28[14 * \mathrm{U}+14 \mathrm{M}]$ & $14 *[\mathrm{R}]$ & 64.4 \\
\hline Ae. tauschii $(\mathrm{DD}) \times S$. cereale $(\mathrm{RR})$ & 28 & $14[\mathrm{D}]$ & $14[\mathrm{R}]$ & 42.1 \\
\hline
\end{tabular}

*In one of the Ae. ovata $\times$ S. cereale amphiploids (plant 3/4), an introgression of Ae. ovata chromatin in the telomeric region of rye chromosomes was observed

(UUMMRR) and Ae. tauschii $\times$ S. cereale (DDRR), were provided by the Institute of Plant Genetics, Polish Academy of Sciences (Poznań, Poland). In this study, 20 plants of each line were used.

For the GISH analysis, seeds of the 20 plants of each amphiploid line were germinated on moist filter paper in Petri dishes. The root-tip chromosome preparations were made according to Pijnacker and Ferwerda (1984). The GISH procedure was carried out according to Schwarzacher and Heslop-Harrison (2000), with modifications, using the genomic DNA of Aegilops spp., labelled (according to the standard oligolabelling protocol) with digoxigenin-11dUTP (Roche) as a probe. Unlabelled genomic DNA from rye ( $S$. cereale cv. Dańkowskie Złote) was sheared by autoclaving and used as a block. The slides were counterstained with PI or DAPI in Vectashields. An Olympus BX 60 epifluorescence microscope fitted with a CCD camera was used to supply documentary evidence.

The number of Aegilops chromosomes was constant and amounted to 28 chromosomes in Ae. kotschyi $\times S$. cereale, Ae. biuncialis (line 1) $\times S$. cereale, Ae. biuncialis (line 2) $\times$ $S$. cereale, Ae. variabilis $\times S$. cereale, Ae. ovata $\times S$. cereale and 14 chromosomes in Ae. tauschii $\times S$. cereale

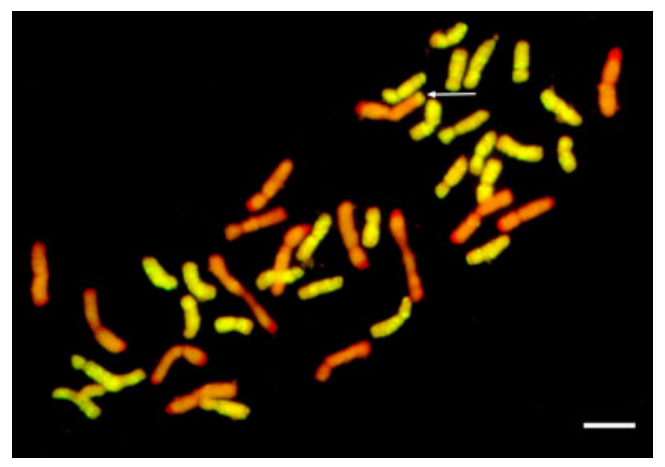

Fig. 1 Genomic in situ hybridisation (GISH) discrimination of the $\mathrm{U}^{\circ} \mathrm{M}^{\circ}$ genome (green) and rye chromosomes (red) in a root-tip cell at mitotic metaphase in an Ae. ovata $\times S$. cereale amphiploid. Introgression of the Ae. ovata chromatin in the telomeric region of a rye chromosome (arrow). Scale bar $=10 \mu \mathrm{m}$ amphiploids. The number of identified rye chromosomes was also constant (14 chromosomes) in three amphiploids: Ae. biuncialis (line 1) $\times S$. cereale, Ae. biuncialis (line 2) $\times$ $S$. cereale and Ae. tauschii $\times S$. cereale. However, the Ae. ovata $\times S$. cereale and Ae. kotschyi $\times S$. cereale amphiploids had 14 to 16 rye chromosomes, while the Ae. variabilis $\times S$. cereale amphiploids had 12 or 14 rye chromosomes (Table 1). In one of the Ae. ovata $\times S$. cereale plants, an introgression of the Ae. ovata chromatin in the telomeric region of a rye chromosome was observed (Figs. 1, 2).

Multi-colour GISH was also applied to distinguish subgenomic (U,S,M) chromosomes of the Aegilops spp. studied. The total genomic DNA of Ae. umbellulata (UU), Ae. sharonensis (SS) and Ae. comosa (MM) was labelled (according to the standard oligolabelling protocol) with digoxigenin-11-dUTP or rhodamine-4-dUTP (Roche) and used as a probe. The GISH protocol was analogous to previous researches. The number of each subgenomic chromosome in a given amphiploid combination (i.e. UU and MM or UU and SS) was constant and amounted to 14. No translocations were identified with one exception (plant no. 3/4 of Ae. ovata $\times S$. cereale), where the introgression

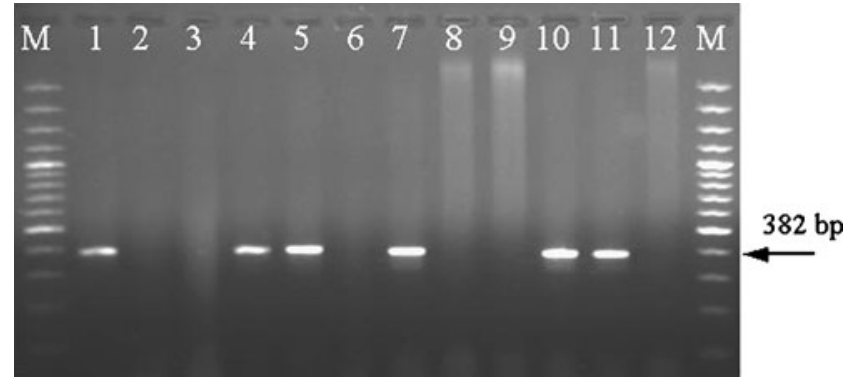

Fig. 2 Amplified products for the CslVrgal3' $F / R$ marker (Lr37). (M) DNA size ladder, (1) Ae. kotschyi, (2) Ae. variabilis, (3) Ae. biuncialis (line 2) (4) Ae. ovata, (5) Ae. biuncialis (line 1), (6) Ae. tauschii, (7) Ae. kotschyi $\times S$. cereale, (8) Ae. variabilis $\times S$. cereale, (9) Ae. biuncialis (line 1) $\times S$. cereale, $(10)$ Ae. ovata $\times S$. cereale, (11) Ae. biuncialis (line $2) \times S$. cereale, $(12)$ Ae. tauschii $\times$ S. cereale. Amplified bands (382 bp) show the presence of $L r 37$ and indicate leaf rust resistance 
of Ae. umbellulata chromatin in the S. cereale chromosome was observed.

Pollen viability was measured as pollen stainability (\%). For each of the 120 plants, four preparations were made by pollen staining with Fulgen liquid. As shown in Table 1, pollen stainability was the highest in Ae. biuncialis (line 1) $\times$ S. cereale $(75.4 \%)$, while it was the lowest in Ae. biuncialis (line 2$) \times S$. cereale $(24.4 \%)$.

The identification of 12 leaf rust resistance genes $(L r 9$, Lr10, Lr19, Lr20, Lr22, Lr28, Lr29, Lr35, Lr37, Lr39, Lr41 and $L r 47)$ was made by using molecular markers according to Błaszczyk et al. (2004, 2008), as well as Chełkowski et al. (2003). Leaf tissues from amphiploids and Aegilops lines (donors of wild chromatin) were sampled three weeks after planting, freeze-dried and used for DNA extraction according to a CTAB-based procedure (Doohan et al. 1998). The leaf rust resistance genes $L r 22, L r 39$ and $L r 41$ were identified in Ae. tauschii and amphiploids: Ae. tauschii $\times S$. cereale, which was consistent with previous reports on the location of $L r 22$, Lr39 and Lr41 in 2DS (Dyck 1979), 2DS (Raupp et al. 2001) and 1D (Singh et al. 2004), respectively. Three lines of Aegilops spp., Ae. kotschyi, Ae. ovata and Ae. biuncialis (line 1), and amphiploids derived from their hybridisation with rye, were found to carry the $\operatorname{Lr} 37$ gene, which is novel (Fig. 2). Previously, the presence of $\operatorname{Lr} 37$ was only reported in chromosome 2NS of Ae. ventricosa (Helguera et al. 2003). However, there was no information about other Aegilops spp. carrying this gene.

The identification of Pchl eyespot resistance genes was made by using endopeptidase assays and molecular markers (Xust SSR2001-7DL), according to Groenewald et al. (2003) and Santra et al. (2006). No Pch1 eyespot resistance genes in the Aegilops lines and in the amphiploids were detected.

In conclusion, the GISH method confirmed the cytogenetic stability of the used amphiploids, and their fertility assessed as pollen viability is also acceptable (with the exception of Ae. variabilis $\times S$. cereale). The results showed that the examined amphiploids could serve as a starting material for the transfer of Aegilops chromatin to cultivated triticale. Furthermore, the amphiploids with transferred leaf rust resistance genes ( $L r 22, L r 39, L r 41$ and Lr37) from Aegilops donors appear to be attractive forms, which can be exploited in future breeding programmes dealing with a widening of genetic diversity in the Triticeae. Given that the $\operatorname{Lr} 37$ gene is closely associated with the yellow rust resistance gene $\mathrm{Yr} 17$ and the stripe rust resistance gene Sr38 in Ae. ventricosa (Seah et al. 2001), it is useful to check the presence of $\operatorname{Yr} 17$ and $\operatorname{Sr} 38$ in the analysed Ae. kotschyi, Ae. ovata and Ae. biuncialis (line 1). The transfer of the Aegilops chromatin by using the described amphiploids (with the leaf rust resistance genes present in the given amphiploids) to cultivated triticale and chromosome identification using fluorescence in situ hybridisation (FISH) with repetitive DNA probes will be the next steps of this research.

Open Access This article is distributed under the terms of the Creative Commons Attribution Noncommercial License which permits any noncommercial use, distribution, and reproduction in any medium, provided the original author(s) and source are credited.

\section{References}

Baalbaki R, Hajj-Hassan N, Zurayk R (2006) Aegilops species from semiarid areas of Lebanon: variation in quantitative attributes under water stress. Crop Sci 46:799-806

Błaszczyk L, Chełkowski J, Korzun V, Kraič J, Ordon F, Ovesná J, Purnhauser L, Tar M, Vida G (2004) Verification of STS markers for leaf rust resistance genes of wheat by seven European laboratories. Cell Mol Biol Lett 9:805-817

Błaszczyk L, Kramer I, Ordon F, Chełkowski J, Tyrka M, Vida G, Karsai I (2008) Validity of selected DNA markers for breeding leaf rust resistant wheat. Cereal Res Commun 36:201-213

Chełkowski J, Golka L, Stępień Ł (2003) Application of STS markers for leaf rust resistance genes in near-isogenic lines of spring wheat cv. Thatcher. J Appl Genet 44:323-338

Dhaliwal HS, Harjit-Singh, William M (2002) Transfer of rust resistance from Aegilops ovata into bread wheat (Triticum aestivum L.) and molecular characterisation of resistant derivatives. Euphytica 126:153-159

Doohan FM, Parry DW, Jenkinson P, Nicholson P (1998) The use of species-specific PCR-based assays to analyse Fusarium ear blight of wheat. Plant Pathol 47:197-205

Dyck PL (1979) Identification of the gene for adult-plant leaf rust resistance in Thatcher. Can J Plant Sci 59:499-501

Gill BS, Sharma HC, Raupp WJ, Browder LE, Hatchett JH, Harvey TL, Moseman JG, Waines JG (1985) Evaluation of Aegilops species for resistance to wheat powdery mildew, wheat leaf rust, Hessian fly and greenbug. Plant Dis 69:314-316

Groenewald JZ, Marais AS, Marais GF (2003) Amplified fragment length polymorphism-derived microsatellite sequence linked to the Pch1 and Ep-D1 loci in common wheat. Plant Breeding 122:83-85

Helguera M, Khan IA, Kolmer J, Lijavetzky D, Zhong-Qi L, Dubcovsky J (2003) PCR assays for the Lr37-Yr17-Sr38 cluster of rust resistance genes and their use to develop isogenic hard red spring wheat lines. Crop Sci 43:1839-1847

Landjeva S, Ganeva G (1999) Identification of Aegilops ovata chromosomes added to the wheat (Triticum aestivum L.) genome. Cereal Res Commun Hungary 271:55-61

Leonard JM, Watson CJW, Carter AH, Hansen JL, Zemetra RS, Santra DK, Campbell KG, Riera-Lizarazu O (2008) Identification of a candidate gene for the wheat endopeptidase Ep-D1 locus and two other STS markers linked to the eyespot resistance gene Pch1. Theor Appl Genet 116:261-270

Miranda LM, Murphy JP, Marshall D, Cowger C, Leath S (2007) Chromosomal location of Pm35, a novel Aegilops tauschii derived powdery mildew resistance gene introgressed into common wheat (Triticum aestivum L.). Theor Appl Genet 114:1451-1456

Molnár I, Schneider A, Molnár-Láng M (2005) Demonstration of Aegilops biuncialis chromosomes in a wheat background by genomic in situ hybridization (GISH) and identification of $\mathrm{U}$ chromosomes by FISH using GAA sequences. Cereal Res Commun Hungary 33:673-680 
Pijnacker LP, Ferwerda MA (1984) Giemsa C-banding of potato chromosomes. Can J Genet Cytol 26:415-419

Prażak R (2007) Evaluation of winterhardiness, earliness and infections with brown rust and powdery mildew in Aegilops species in eastern Poland. Zesz Probl Post Nauk Rol 517:603-612 (in Polish)

Raupp WJ, Sukhwinder-Singh, Brown-Guedira GL, Gill BS (2001) Cytogenetic and molecular mapping of the leaf rust resistance gene Lr39 in wheat. Theor Appl Genet 102:347-352

Santra DK, Watt C, Little L, Kidwell KK, Campbell KG (2006) Comparison of a modified assay method for the endopeptidase marker Ep-D1b with the Sequence Tag Site marker XustSSR2001$7 D L$ for strawbreaker foot rot resistance in wheat. Plant Breeding 125:13-18

Schneider A, Molnár I, Molnár-Láng M (2008) Utilisation of Aegilops (goatgrass) species to widen the genetic diversity of cultivated wheat. Euphytica 163:1-19
Schwarzacher T, Heslop-Harrison P (2000) Practical in situ hybridization. BIOS Scientific Publishers Ltd., Oxford

Seah S, Bariana H, Jahier J, Sivasithamparam K, Lagudah ES (2001) The introgressed segment carrying rust resistance genes $\operatorname{Yr} 17, \operatorname{Lr} 37$ and $\operatorname{Sr} 38$ in wheat can be assayed by a cloned disease resistance gene-like sequence. Theor Appl Genet 102:600-605

Singh S, Franks CD, Huang L, Brown-Guedira GL, Marshall DS, Gill BS, Fritz A (2004) Lr41, Lr39, and a leaf rust resistance gene from Aegilops cylindrica may be allelic and are located on wheat chromosome 2DS. Theor Appl Genet 108:586-591

Wojciechowska B, Pudelska H (2005) Production and characterization of amphiploids of Aegilops kotschyi and Ae. biuncialis with Secale cereale, and of backcross hybrids of Ae. biuncialis $\times S$. cereale amphiploids with $2 \times$ and $4 \times S$. cereale. J Appl Genet 46:157-161 